\title{
Osteoprotegerin gene polymorphism is not associated with prosthetic joint infection after total joint arthroplasty in the Czech population
}

\author{
Zdenka Navratilova ${ }^{\mathrm{a}}$, Jiri Gallo ${ }^{\mathrm{b}}$, Matej Smizansky ${ }^{\mathrm{b}}$, Frantisek Mrazek ${ }^{\mathrm{a}}$, Martin Petrek $^{\mathrm{a}}$
}

\begin{abstract}
Background and aims. Osteoprotegerin (OPG; official gene symbol: TNFRSF11B) is considered a negative regulator of bone resorption via inhibition of osteoclast differentiation. Further, OPG expression has been detected in Prosthetic Joint Infection (PJI) a serious complication limiting the overall outcome of total joint arthroplasty (TJA). As OPG may be a candidate molecule for PJl pathogenesis, we investigated whether genetic variation in the OPG promoter, namely the SNP at position -163 was associated with PJI.
\end{abstract}

Methods. OPG -163 T/C SNP (rs3102735) was genotyped by polymerase chain reaction with sequence specific primers (PCR-SSP) in 98 Czech patients with PJI and two Czech control groups: 1) aseptic TJA control [251 patients with TJA who did not develop PJI at least $6 \mathrm{yrs}$. after the surgery] and 2) population control (185 healthy control subjects without TJA). Results. The distribution of OPG -163 SNP genotypes complied with the Hardy-Weinberg equilibrium in all three groups. The allele frequencies of OPG -163 SNP were similar in patients with PJI (minor allele frequency: 0.14), those with aseptic TJA (0.13) and population controls $(0.14, P>0.05)$. Further, there was no significant difference in genotype or phenotype frequency (carriage rate) between patients with $\mathrm{PJl}$ and both control groups $(P>0.05)$.

Conclusions. In a Czech population, the OPG -163 T/C SNP has not been found to be associated with PJI.

Key words: osteoprotegerin, RANKL-RANK-OPG axis, prosthetic joint infection, DNA sequence variant, TNFRSF11B, arthroplasty, single nucleotide polymorphism, osteoimmunology

Received: January 12, 2012; Accepted: February 15, 2012; Available online: April 18, 2012

http://dx.doi.org/10.5507/bp.2012.024

aLaboratory of Immunogenomics and Imunoproteomics, Department of Immunology, Faculty of Medicine and Dentistry, Palacky University Olomouc, Czech Republic

${ }^{b}$ Department of Orthopaedics, Faculty of Medicine and Dentistry, Palacky University Olomouc and University Hospital Olomouc Corresponding author: Martin Petrek, e-mail: martin.petrek@fnol.cz

\section{INTRODUCTION}

Prosthetic joint infection (PJI) is a serious complication threatening both the early and late period after total joint arthroplasty (TJA). Current estimates suggest that despite careful management to avoid all sources of infection, PJI can develop in up to $1.7 \%$ of primary hip arthroplasties and $2.5 \%$ of primary knee arthroplasties ${ }^{1}$. Given that each year at least two millions TJAs are performed worldwide, the number of infected cases is enormous and is predicted to increase ${ }^{2}$.

PJI is caused by bacterial colonisation of the prosthetic joint. Regardless of particular route of infection it is clear that host factors may increase the risk of PJI by compromising the immune response ${ }^{3}$. Bacteria and their products are also potent inducers of bone resorption. Experimentally, significant reduction in bone mineral density shortly after the beginning of Staphylococcus aureus infection of the bone has been revealed ${ }^{4}$. This was effectively prevented by inhibition of RANKL (receptor activator of nuclear factor - kappa B ligand) signalling. This and other experiments support the clinical observation of a tight association between the development of infection and increased resorption of periprosthetic bone $\mathrm{e}^{5}$. For this reason, cytokine ligands and the corresponding receptors that regulate osteoclast accumulation, maturation and viability, are probably involved in the complex pathogenesis of PJI. The axis RANK-RANKL-OPG is the key regulator of the bone multicellular unit, and genetic factors related to this axis have been shown to affect bone mineral density ${ }^{6-8}$, osteoporosis ${ }^{7}$ and periprosthetic osteolysis ${ }^{9}$. A recent study demonstrated deregulation of OPG expression in osteoblasts after Staphylococcus aureus infection ${ }^{10}$. Also, expression of OPG was observed in periprosthetic interface membranes retrieved from septic prostheses ${ }^{11}$.

Osteoprotegerin ( $O P G$; official gene symbol: TNFRSF11B) acts as a soluble decoy receptor that blocks binding of RANKL to its receptor (RANK) inhibiting osteoclast differentiation. The human OPG represents a single copy gene located on chromosome 8 (8q24). It spans $29 \mathrm{~kb}$ and consists of 5 exons, 4 introns, and is transcribed into four transcripts, $2.4 \mathrm{~kb}$ one representing the major transcript ${ }^{12}$. There is a degree of genetic variation in the gene with at least 10 SNP localised mostly within the 5 ' flanking region and also exons/introns ${ }^{13}$. A plausible contribution of a genetic variation in the $O P G$ gene to PJI has so far been investigated only in a single centre and with inconsistent results ${ }^{9,14}$. In agreement with the current rules for conducting genetic association stud- 
ies ${ }^{15}$, and especially those relevant to areas of rheumatology and osteoimmunology ${ }^{16}$, we therefore investigated if $O P G-163 \mathrm{~T} / \mathrm{C}$ polymorphism is associated with PJI in a Czech population.

\section{MATERIAL AND METHODS}

\section{Study population}

$O P G-163$ SNP T/C (rs3102735) was genotyped in 98 patients with PJI and two control groups: i) aseptic TJA control (251 patients with TJA who did not develop PJI at least 6 yrs. after the surgery) and ii) population control (185 healthy control subjects without TJA). Of 98 infected cases, 16 patients were recruited at the Dept. of Orthopaedics Frýdek Místek and Znojmo, Czech Republic. Both patients and controls were unrelated individuals of Czech origin. Clinical and laboratory characteristics of patients with PJI and controls are listed in Table 1. PJI was diagnosed according to the following criteria $^{17}:$ i) presence of sinus tract communicating with a joint and/or intra-articular pus; ii) coincidentally positive results of histological examination (five or more neutrophils per high power field) and culture of intraoperative samples; iii) if only intraoperative culture or histological results were positive, then at least two of the following signs had to be present: high clinical suspicion of infection (acute onset, fever, erythema, edema, persistent local pain, early prosthetic failure, wound healing disturbances, etc.), erythrocyte sedimentation rate $>30 \mathrm{~mm} /$ hr, C-reactive protein elevated more than 1.5 times above the laboratory reference value, positive $99 \mathrm{~m}$ Technetium leukocyte scintigraphy (the last criterion included only in patients from the University Hospital Olomouc). Patients without PJI did not fulfil these criteria.

Informed consent for the anonymous use of their DNA for the purposes of this study was obtained from all subjects. The study was performed with the approval of the local Ethics Committee.

\section{Genotyping}

Polymerase chain reaction with sequence specific primers (PCR-SSP) was used to genotype $O P G-163 \mathrm{~T} / \mathrm{C}$ SNP (rs3102735). Standard and mutant alleles were amplified in two separate reactions. The constant reverse primer ( 5 ' tcaccttccttccttgaatc 3') was used for amplification with forward specific primers either for the standard allele (5' gttcgetgtctccccatt 3') or for the minor allele (5'gttcgctgtctcccccatc 3'). Reaction conditions and internal controls for PCR-SSP were adopted from Phototyping methodology ${ }^{18}$, the cycling profile consisted of initial denaturation $\left(96^{\circ} \mathrm{C}, 1 \mathrm{~min}\right)$ followed by first five cycles $\left(96{ }^{\circ} \mathrm{C}-20 \mathrm{~s}, 70{ }^{\circ} \mathrm{C}-45 \mathrm{~s}, 72{ }^{\circ} \mathrm{C}-25 \mathrm{~s}\right.$ ), further 21 cycles $\left(96{ }^{\circ} \mathrm{C}-25 \mathrm{~s}, 65^{\circ} \mathrm{C}-50 \mathrm{~s}, 72{ }^{\circ} \mathrm{C}-30 \mathrm{~s}\right)$ and final four cycles $\left(96^{\circ} \mathrm{C}-30 \mathrm{~s}, 55^{\circ} \mathrm{C}-1 \mathrm{~min}, 72^{\circ} \mathrm{C}-1 \min 30 \mathrm{~s}\right)$.

\section{Statistics}

The significance of differences in allelic, genotype and phenotype frequencies between all groups was determined by means of the $\chi 2$ test applying the Woolf-Haldane correction for small numbers. The relative ratio (RR), 95\% confidence interval (CI) and $P$-value were calculated. The statistical power was determined according to the protocol described elsewhere ${ }^{19}$.

\section{RESULTS}

The distribution of alleles, genotypes, and phenotypes of $O P G-163$ SNP in patients with PJI and two control samples is presented in Table 2. The distribution of $O P G$ -163 SNP genotypes complied with the Hardy-Weinberg equilibrium in all three groups. The allele frequencies of $O P G-163$ SNP were similar in the patients with PJI (minor $\mathrm{C}$ allele frequency: 0.14), those with aseptic TJA (0.13) and population controls as well $(0.14, P>0.05)$. Further, the genotype and phenotype frequency (carriage rate) did not differ between the patients with PJI and either of the two control groups $(P>0.05)$.

When the patients with PJI were stratified according to the affected joint, there was no association between $O P G-163$ SNP and PJI of Total Hip Arthroplasty - C allele frequency was equal in both aseptic THA and in THA/PJI groups: $0.12 ; P>0.05)$. Similarly, the distribution of $O P G-163$ SNP did not differ between the patients with aseptic Total Knee Arthroplasty (TKA, C allele frequency: 0.14$)$ and those with TKA/PJI $(0.16 ; P>0.05)$.

The statistical power of the present study to replicate observations reported for the British population in the initial report ${ }^{9}$ was higher than $99 \%$. The power to detect differences between cases and controls was $94 \%$ if aiming at an odds ratio (OR) 2.0, and 82\% for OR 1.75 .

\section{DISCUSSION}

The results show no association between $-163 \mathrm{~T} / \mathrm{C}$ single nucleotide polymorphism in the Osteoprotegerin gene and the risk of prosthetic joint infection. This finding may be interpreted in two ways, either 1) "individually" as an independent study of a candidate SNP in the $O P G$ gene in the Czech population, or 2) in the context of previously reported controversial data from the British population: Here, Malik et al. ${ }^{9}$ first reported $O P G-163$ as a risk factor for PJI. However only after three years Malik et al. ${ }^{14}$ published a brief note that this was/might not be true due to "inadvertent data manipulation".

Given the fact, that the latter brief note ${ }^{14}$ was not formulated as a typical erratum statement and thus has not been linked to the original report ${ }^{9}$ in databases such as PubMed, the association between the investigated polymorphism and PJI can still be considered to be present in the "universe" of genetic association data as it may be exemplified e.g. by the current review ${ }^{20}$. Thus, in our opinion, and in accordance to the appropriate "guidelines" (ref. ${ }^{15-16,20}$ ) the replication of these data coming from a single centre is required to prove there is adequate statistical power. If we understood our current work as a 
Table 1. Characteristics of Czech patients with PJI and two control groups of the patients with aseptic TJA and Czech population controls.

\begin{tabular}{lccc}
\hline & $\begin{array}{c}\text { Population controls } \\
\mathrm{n}=185\end{array}$ & $\begin{array}{c}\text { Aseptic TJA } \\
\mathrm{n}=251\end{array}$ & $\begin{array}{c}\text { PJI } \\
\mathrm{n}=98\end{array}$ \\
\hline Gender; men/women & $87 / 98$ & $78 / 173$ & $49 / 49$ \\
Age at index surgery; years & $28(24-34)$ & $49(43-54)$ & $67(58-73)$ \\
Joint; hip/knee/other* & 0 & $203 / 48 / 0$ & $43 / 52 / 3$ \\
BMI (median) & n.a. & $28(25-30)$ & $29(26-30)$ \\
Primary diagnosis: & & & 74 \\
Osteoarthritis & 0 & 91 & 10 \\
Dysplastic joint & 0 & 113 & 3 \\
Inflammatory joint & 0 & 13 & 11 \\
Other diagnosis & 0 & 34 & 56 \\
Comorbidity: & & & 12 \\
Nothing & 185 & 157 & 30 \\
Diabetes mellitus & 0 & 22 & 58 \\
Other+ & 0 & 72 & 19 \\
Intraoperative culture: & & & 21 \\
Staphylococci & n.a. & 0 & \\
Other pathogens & n.a. & 0 & 24 \\
Negative & n.a. & 251 & 43 \\
Type of PJI: & & & 22 \\
Early & n.a. & n.a. & 9 \\
Delayed & n.a. & n.a. & n.a. \\
Haematogenous & n.a. & n.a. & \\
Other & n.a. & & \\
\hline
\end{tabular}

Legend: Continuous data presented as median with interquartile $\left(1^{\text {st }}\right.$ to $\left.3^{\text {rd }}\right)$ range in parentheses. * Shoulder, elbow, + e.g. rheumatoid arthritis and nicotine addiction, n.a., not applicable; BMI, body mass index.

Table 2. Genotype, allele and phenotype (carriage rates) frequencies of the OPG -163 SNP in the patients with PJI and two control groups of the patients with aseptic TJA and Czech population controls.

\begin{tabular}{lccccccc}
\hline Frequency & \multicolumn{3}{c}{ Genotype } & \multicolumn{2}{c}{ Allele } & \multicolumn{2}{c}{ Phenotype } \\
\hline $\begin{array}{l}-163 \mathrm{~T} / \mathrm{C} \\
\text { rs3102735 }\end{array}$ & $\mathrm{TT}$ & $\mathrm{TC}$ & $\mathrm{CC}$ & $\mathrm{T}$ & $\mathrm{C}$ & $\mathrm{T}$ & $\mathrm{C}$ \\
\hline $\begin{array}{l}\text { Population controls } \\
\text { (n=185) }\end{array}$ & $0.72(133)$ & $0.28(51)$ & $0.00(1)$ & $0.86(317)$ & $0.14(53)$ & $0.99(184)$ & $0.28(52)$ \\
$\begin{array}{l}\text { Aseptic TJA } \\
(\mathrm{n}=251)\end{array}$ & $0.76(191)$ & $0.23(57)$ & $0.01(3)$ & $0.87(439)$ & $0.13(63)$ & $0.99(248)$ & $0.24(60)$ \\
$\begin{array}{l}\text { PJI } \\
(\mathrm{n}=98)\end{array}$ & $0.73(72)$ & $0.25(24)$ & $0.02(2)$ & $0.86(168)$ & $0.14(28)$ & $0.98(96)$ & $0.27(26)$ \\
\hline
\end{tabular}

The data are given as frequency of a particular genotype/allele/phenotype with absolute numbers in parentheses.

replication, it was important to note that we investigated a larger number of patients with PJI ( $\mathrm{n}=98)$ than the original British study $(\mathrm{n}=63)$. Thus the statistical power of our study was more than adequate ( $>99 \%)$ to replicate the association of PJI with $O P G-163$ SNP observed in the original, first British report ${ }^{9}$.

It may be argued that despite the low public visibility of the "corrected" data, a replication study cannot be performed in the present. However, if we consider our study merely as an individual undertaking aimed at the assessment of the plausible association between $O P G-163$ T/C SNP and PJI, it has very good power (94\%) to detect association in the range of OR values around 2.0, and is still adequately powered around OR $1.7(81 \%)$; the acceptable limit being $80 \%\left(\right.$ ref. $\left.{ }^{19}\right)$. For the detection of weaker associations (OR <1.7), however, the number of study subjects will have to be increased which we acknowledge is a limitation of the study.

We cannot exclude the possibility that the observed lack of genetic association between $O P G-163$ SNP and 
PJI in our Czech cohort was due to inappropriately targeted selection of candidate SNP. Indeed, it has been very recently reported that the $O P G-163 \mathrm{~T} / \mathrm{C}$ may not affect the expression of the $O P G$ gene $^{6}$, however this was an isolated in vitro report. In this context, there are more SNPs located on the $O P G$ gene ${ }^{13}$, However the data on their functionality and mutual relationships are mostly limited to non-Caucasian populations ${ }^{21,22}$.

\section{CONCLUSION}

In conclusion, even if the present study had sufficient statistical power both as an individual "exercise" and/or a replication study, it provided no further evidence that $O P G-163 \mathrm{~T} / \mathrm{C}$ SNP is associated with prosthetic joint infection. After more information is obtained on the spectrum of genetic variation in the $O P G$ gene, analyses with further SNPs may allow us to draw definite conclusion about a possible role of Osteoprotegerin genetic variation in PJI.

\section{ACKNOWLEDGEMENTS}

This study was presented at the 25th European Immunogenetics and Histocompatibility Conference (EFI), 4-7 May 2011, Prague, Czech Republic. The technical help of the staff of the Orthopaedics Departments of the following hospitals: Olomouc, Frýdek-Místek and Znojmo, is gratefully acknowledged. The investigations were supported by grants from the Czech Science Foundation to Z.N. (GACR 310/09/P377) and from the Czech Ministry of Health to M.P. (IGA MZCR NS10260).

\section{CONFLICT OF INTEREST STATEMENT}

The authors state that there are no conflicts of interest regarding the publication of this article.

\section{REFERENCES}

1. Kurtz SM, Ong KL, Lau E, Bozic KJ, Berry D, Parvizi J. Prosthetic joint infection risk after TKA in the Medicare population. Clin Orthop Relat Res 2010;468:52-6.

2. Kurtz SM, Lau E, Schmier J, Ong KL, Zhao K, Parvizi J. Infection burden for hip and knee arthroplasty in the United States. J Arthroplasty 2008;23:984-91.

3. Zimmerli W, Sendi P. Pathogenesis of implant-associated infection: the role of the host. Semin Immunopathol 2011;33:295-306.

4. Verdrengh M, Bokarewa M, Ohlsson C, Stolina M, Tarkowski A. RANKL-targeted therapy inhibits bone resorption in experimental Staphylococcus aureus-induced arthritis. Bone 2010;46:752-8.

5. Wright JA, Nair SP. Interaction of staphylococci with bone. Int J Med Microbiol 2010;300:193-204.
6. Takacs I, Lazáry A, Kósa JP, Kiss J, Balla B, Nagy Z, Bácsi K, Speer G, Lakatos P. Allelic variations of RANKL/OPG signaling system are related to bone mineral density and in vivo gene expression. Eur J Endocrinol 2010;162:423-31.

7. Richards JB, Rivadeneira F, Inouye M, Pastinen TM, Soranzo N, Wilson SG, Andrew T, Falchi M, Gwilliam R, Ahmadi KR, Valdes AM, Arp P, Whittaker $P$, Verlaan DJ, Jhamai M, Kumanduri V, Moorhouse M, van Meurs JB, Hofman A, Pols HA, Hart D, Zhai G, Kato BS, Mullin $\mathrm{BH}$, Zhang F, Deloukas $\mathrm{P}$, Uitterlinden AG, Spector TD. Bone mineral density, osteoporosis, and osteoporotic fractures: a genome-wide association study. Lancet 2008;371:1505-12.

8. Paternoster L, Lorentzon M, Vandenput L, Karlsson MK, Ljunggren O, Kindmark A, Mellstrom D, Kemp JP, Jarett CE, Holly JM, Sayers A, St Pourcain B, Timpson NJ, Deloukas P, Davey Smith G, Ring SM, Evans DM, Tobias JH, Ohlsson C. Genome-wide association meta-analysis of cortical bone mineral density unravels allelic heterogeneity at the RANKL locus and potential pleiotropic effects on bone. PLoS Genet 2010;6:e1001217.

9. Malik MH, Bayat A, Jury F, Ollier WE, Kay PR. Genetic susceptibility to hip arthroplasty failure--association with the RANK/OPG pathway. Int Orthop 2006;30:177-81.

10. Young AB, Cooley ID, Chauhan VS, Marriott I. Causative agents of osteomyelitis induce death domain-containing TNF-related apoptosis-inducing ligand receptor expression on osteoblasts. Bone 2011;48:857-63.

11. Gehrke T, Sers C, Morawietz L, Fernahl G, Neidel J, Frommelt L, Krenn V. Receptor activator of nuclear factor kappaB ligand is expressed in resident and inflammatory cells in aseptic and septic prosthesis loosening. Scand J Rheumatol 2003;32:287-94.

12. Morinaga T, Nakagawa N, Yasuda H, Tsuda E, Higashio K. Cloning and characterization of the gene encoding human osteoprotegerin/ osteoclastogenesis-inhibitory factor. Eur J Biochem 1998;254:685-91.

13. Hagedorn C, Telgmann R, Dördelmann C, Schmitz B, Hasenkamp S, Cambien F, Paul M, Brand E, Brand-Herrmann SM. Identification and functional analyses of molecular haplotypes of the human osteoprotegerin gene promoter. Arterioscler Thromb Vasc Biol 2009;29:1638-43

14. Malik M. Genetic susceptibility to hip arthroplasty failure-association with the RANK/OPG pathway. Int Orthop 2009;33:297.

15. von Elm E, Moher D, Little J; STREGA collaboration. Reporting genetic association studies: the STREGA statement. Lancet 2009;374:98-100.

16. Plenge RM, Bridges SL Jr, Huizinga TW, Criswell LA, Gregersen PK. Recommendations for publication of genetic association studies in Arthritis \& Rheumatism. Arthritis Rheum 2011;63:2839-47.

17. Gallo J, Kolar M, Dendis M, Loveckova Y, Sauer P, Zapletalova J, Koukalova D. Culture and PCR analysis of joint fluid in the diagnosis of prosthetic joint infection. New Microbiol 2008;31:97-104.

18. Bunce $M, O^{\prime}$ Neill CM, Barnardo MC, Krausa P, Browning MJ, Morris PJ, Welsh KI. Phototyping: comprehensive DNA typing for HLA-A, B, C, DRB1, DRB3, DRB4, DRB5 \& DQB1 by PCR with 144 primer mixes utilising sequence-specific primers (PCR-SSP). Tissue Antigens 1995;46:355-67.

19. Lalouel JM, Rohrwasser A. Power and replication in case-control studies. Am J Hypertens 2002;15:201-5.

20. Del Buono A, Denaro V, Maffulli N. Genetic susceptibility to aseptic loosening following total hip arthroplasty: a systematic review. $\mathrm{Br}$ Med Bull 2011 Jun 7. [Epub ahead of print]

21. Kim JG, Kim JH, Kim JY, Ku SY, Jee BC, Suh CS, Kim SH, Choi YM. Association between osteoprotegerin (OPG), receptor activator of nuclear factor-kappaB (RANK), and RANK ligand (RANKL) gene polymorphisms and circulating OPG, soluble RANKL levels, and bone mineral density in Korean postmenopausal women. Menopause 2007;14:913-8.

22. Eun IS, Park WW, Suh KT, Kim JI, Lee JS. Association between osteoprotegerin gene polymorphism and bone mineral density in patients with adolescent idiopathic scoliosis. Eur Spine J 2009;18:1936-40. 